\title{
USE OF RECYCLED POLYMERS FOR ENCAPSULATION OF RADIOACTIVE, HAZARDOUS AND MIXED WASTES
}

\section{FINAL REPORT}

P.R. Lageraaen and P.D.Kalb

November 1997

Prepared by:

Brookhaven National Laboratory

Environmental \& Waste Technology Center

Prepared for:

New York State Department of Economic Development Office off Recycling Market Development

U.S. Department of Energy

Contract No. DE-AC02-98CH10886 



\title{
USE OF RECYCLED POLYMERS FOR ENCAPSULATION OF RADIOACTIVE, HAZARDOUS AND MIXED WASTES
}

FINAL REPORT

\author{
P.R. Lageraaen and P.D. Kalb \\ Contributors: \\ J. W. Adams \\ M. Fuhrmann \\ L. Milian \\ C. Weber \\ S.P. Yim
}

November 1997

Prepared by:

Brookhaven National Laboratory

Environmental \& Waste Technology Center

Prepared for:

New York State Department of Economic Development

Office of Recycling Market Development 


\begin{abstract}
Polyethylene encapsulation is a waste treatment technology developed at Brookhaven National Laboratory using thermoplastic polymers to safely and effectively solidify hazardous, radioactive and mixed wastes for disposal. Over 13 years of development and demonstration with surrogate wastes as well as actual waste streams on both bench and full scale have shown this to be a viable and robust technology with wide application. Process development efforts have previously focused on the use of virgin polymer feedstocks. In order to potentially improve process economics and serve to lessen the municipal waste burden, recycled polymers were investigated for use as encapsulating agents. Recycled plastics included low-density polyethylene, linear low-density polyethylene, high-density polyethylene and polypropylene, and were used as a direct substitute for or blended together with virgin resin. Impacts on processing and final waste form performance were examined.
\end{abstract}




\section{TABLE OF CONTENTS}

ABSTRACT $\ldots \ldots \ldots \ldots \ldots \ldots \ldots \ldots \ldots \ldots \ldots \ldots \ldots \ldots \ldots \ldots \ldots \ldots \ldots \ldots$

1. INTRODUCTION $\ldots \ldots \ldots \ldots \ldots \ldots \ldots \ldots \ldots \ldots \ldots \ldots \ldots \ldots \ldots \ldots \ldots \ldots$

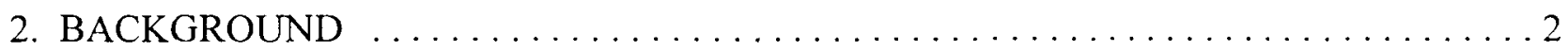

2.1 Polymer Encapsulation Process Description $\ldots \ldots \ldots \ldots \ldots \ldots \ldots \ldots \ldots \ldots \ldots$

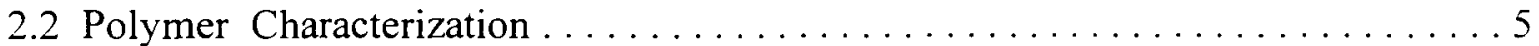

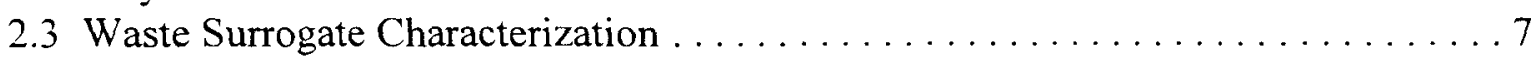

3. RECYCLE POLYMER PROCESSING $\ldots \ldots \ldots \ldots \ldots \ldots \ldots \ldots \ldots \ldots \ldots \ldots \ldots$

4. PRODUCT CHARACTERIZATION AND PERFORMANCE $\ldots \ldots \ldots \ldots \ldots \ldots \ldots$

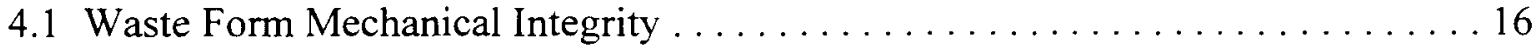

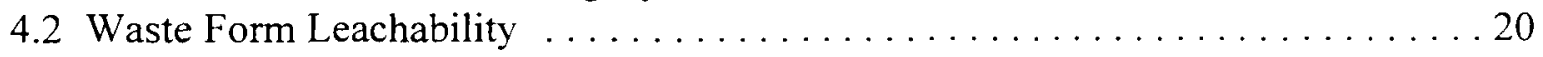

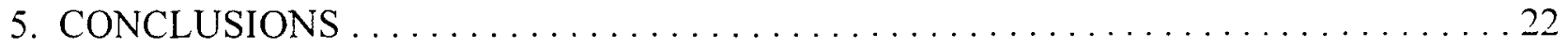

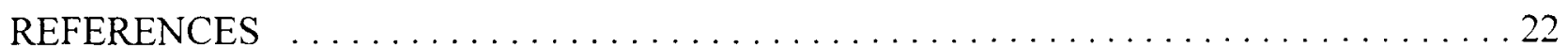




\section{LIST OF FIGURES}

Figure 2.1. Sketch of kinetic mixer used during processibility testing $\ldots \ldots \ldots \ldots \ldots \ldots 4$

Figure 2.2. Kinetic mixer installed at BNL's Environmental \& Waste Technology Center . . . . 4

Figure 4.1. ALT leach results for waste forms containing $50 \mathrm{wt} \% \mathrm{RFP}$ surrogate $\ldots \ldots \ldots 20$ 


\section{LIST OF TABLES}

Table 2.1. Quantity and source of recycled plastic procured for encapsulation testing . . . . 6

Table 2.2. Recycled plastic melt indices $(\mathrm{g} / 10 \mathrm{~min}) \ldots \ldots \ldots \ldots \ldots \ldots \ldots \ldots \ldots$

Table 2.3. Chemical composition of RFP surrogate $\ldots \ldots \ldots \ldots \ldots \ldots \ldots \ldots \ldots \ldots$

Table 3.1. Testing conditions and product density results for R-LDPE (JAM Plastics) . . . 10

Table 3.2. Testing conditions and product density results for Clearzon IM8 Recycled HDPE . 11

Table 3.3. Testing conditions and product density results for Forrester recycled HDPE . . . . 13

Table 3.4. Testing conditions and product density results for Clearzon CP recycled HDPE . . 13

Table 3.5. Testing conditions and product density results for Resource recycled LLDPE . . . . 14

Table 3.6. Testing conditions and product density results for Pure Tech recycled PP/HDPE . . 14

Table 4.1. Compressive strength of recycled plastic waste forms $\ldots \ldots \ldots \ldots \ldots \ldots \ldots$

Table 4.2. Accelerated Leach Test results; CFL versus time for recycled plastic waste forms . 19

Table 4.3. Comparison of CFL for $\mathrm{Na}$ at ALT completion and 300 year extrapolation . . . . . 20 


\section{INTRODUCTION}

Feasibility testing was conducted at the Brookhaven National Laboratory (BNL) Environmental \& Waste Technology Center (EWTC) for using recycled polymers in place of virgin thermoplastic materials for waste encapsulation. This work was sponsored by the New York State Department of Economic Development, Office of Recycling Market Development and the U.S. Department of Energy Mixed Waste Focus Area (EM-50) under Technical Task Plan (TTP) CH36MW63.

Polymer encapsulation is a waste treatment technology developed at BNL using thermoplastic polymers to safely and effectively solidify hazardous, low-level radioactive and lowlevel mixed wastes for disposal. Mixed wastes include both hazardous and radioactive contaminants. Solidification of wastes through polymer encapsulation permits the disposal of these wastes in accordance with Land Disposal Requirements as promulgated by the U.S. Environmental Protection Agency (US EPA). Over 13 years of development and demonstration with surrogate wastes as well as actual waste streams on both bench and full scale have shown polymer encapsulation to be a viable and robust technology with wide application. Traditionally, processing has been accomplished through the use of extrusion although recent advances with an alternative thermoplastic processing method, kinetic mixing, as investigated during this effort, has served to augment the usefulness of polymer encapsulation. Attention during process development has focused on the use of virgin polymer feedstocks, primarily injection-molding grade low-density polyethylene (LDPE).

Polymers are generally inert, permit high waste loadings compared with conventional cementitious encapsulation, and durable providing excellent waste form characteristics such as low leachability and good compressive and tensile strength, an important consideration for hydrophilic wastes. During this investigation, recycled polymers were studied for use as encapsulating agents in order to potentially improve process economics, provide a valuable new market for nonbiodegradable plastics, reduce the usage of valuable petroleum resources and lessen the municipal waste burden. The recycled plastics tested were all post-consumer or post-industrial and included low-density polyethylene (LDPE), linear low-density polyethylene (LLDPE), high-density polyethylene (HDPE) and polypropylene (PP). Recycled plastics were used as a direct substitute for virgin resin or in a selected proportion with virgin resin based on expected processing characteristics. Impacts on processing parameters and final waste form performance were examined. 


\section{BACKGROUND}

\subsection{Polymer Encapsulation Process Description}

The polymer encapsulation process uses thermoplastics to stabilize waste materials within a polymer matrix. This is accomplished by heating the thermoplastic above its melting point, then mixing the molten polymer with the waste. Solidification of the encapsulated matrix is assured upon cooling and is independent of the chemical nature of the waste materials. Thermoplastics, in general, are polymers that once heated above their melting point, can be shaped and formed while in a viscous state, then harden upon cooling. This process can be performed repeatedly. Polyethylene, with a melting point of approximately $120^{\circ} \mathrm{C}$, has been the predominant polymer used during encapsulation process development studies due to its low cost, processing ease and excellent durability.

Mechanically mixing waste materials with a viscous polymer and processing the mixture can be accomplished by the use of extrusion or kinetic mixing. Through the use of continuous extrusion, a versatile, industry-tested process, dry waste and polymer, e.g., polyethylene, are continuously fed to the extruder feedthroat by individual dynamic feeders. Precise control can be maintained by the feeders to accurately meter the polymer and waste material to the extruder and to maintain a constant waste loading. Within the extruder, a variable speed screw mixes the molten polyethylene with the waste material, builds pressure, and pumps the homogeneous mixture through an output die. Posttreatment of the product from the extruder is not necessary and the extrudate can be collected directly in a waste container. Natural cooling of the extruder product results in a solid monolithic waste form suitable for disposal. The processing temperature is controlled through independent temperature zones and can be tailored to achieve a particular temperature profile for different polymers. For example, low-density polyethylene (LDPE) with a melting point of approximately $115^{\circ} \mathrm{C}$ is processed at approximately $115-170^{\circ} \mathrm{C}$ whereas high-density polyethylene (HDPE) with a higher melting point of approximately $135^{\circ} \mathrm{C}$ would require a correspondingly higher temperature profile in the extruder.

The application of thermoplastic encapsulation to a wide range of different waste types is due to the inert nature of the plastics so chemical incompatibilities between the waste and encapsulating agent are not an issue, as is the case for waste stabilization technologies such as cementation. For extrusion, the only process limitations are the moisture content and particle size of the wastes. Moisture in excess of approximately $2 \%$ must be removed prior to processing. This is because extruders are not designed for devolatilization. The particle size distribution of the waste must not contain an excess of fines with a particle size less than approximately $50 \mu \mathrm{m}$ since it is difficult to coat/"wet" and mix the fine particles with the viscous melt. The upper particle size limit is approximately $2000 \mu \mathrm{m}$ but is dependent on the size of the extruder. A particle size distribution with an excess of large particles will have a deleterious impact on waste form leachability. Kinetic mixing as an alternative processing method is currently being investigated, as part of this co-funded effort, since it promises to improve upon these limitations. 
Kinetic mixing is a batch polymer processing technique that uses high shear and rapid rotational motion to create frictional heat sufficient to volatilize moisture and melt thermoplastics. Polymer and waste are fed to the mixer feed throat batch-wise, rapidly brought to melt temperature, and mixed, then discharged as a homogeneous molten mass. The product may be suitable for final disposal or secondary treatment or handling, e.g., extrusion or compression molding, may be necessary. As with extrusion processing, solidification of the product is assured on cooling. The robust agitation and mixing action potentially makes kinetic processors less sensitive to particle size limitations. Due to the design of the mixer, moisture can be evolved prior to melting the polymers as frictional heat is used to overcome the latent heat of vaporization. Since the polymer does not begin to melt until the moisture is vaporized, gases do not tend to become entrained in the molten product. Cycle time is dependent upon the feed composition, batch size and moisture content. Abrasive materials and increasing the batch size will decrease cycle time due to improved friction. Increasing the moisture content will, as expected, increase the cycle time since frictional heat will be used to evolve the moisture. This technology is an ideal candidate for substituting various polymers such as recycled plastics because the feed materials can be altered on a batch-to-batchbasis with minimal modification to the operating procedure. The operating temperature of the mixer is not pre-set so materials will melt and mix following sufficient kinetic energy generation. For example, substituting a thermoplastic with a higher melting point will simply require a slightly longer cycle time.

Feasibility testing with waste surrogates and recycled plastics was conducted using a pilotscale kinetic mixer rated at approximately $450 \mathrm{~kg} / \mathrm{hr}(1000 \mathrm{lb} / \mathrm{hr})$. The mixer was manufactured by LEX Technologies, Brampton, Ontario, Canada and was supplied by EcoLEX, Inc of Jacksonville, FL. It has a $10 \mathrm{~L}$ batch mixing chamber, helical screw feed section, $7 \mathrm{~cm}$ rotating shaft with 4 mixing paddles, water cooled bearings, and pneumatically controlled inlet slide gate and discharge door. The shaft, powered by a $150 \mathrm{HP}$ electric motor, rotates at a constant revolution resulting in a paddle tip speed of approximately $40 \mathrm{~m} / \mathrm{sec}$. Operation is controlled by a programmable logic controller (PLC), enabling the operator to coordinate feeding, charging, mixing and discharging of the materials. Charge and discharge functions can be automated based on motor load sensing (ammeter), a temperature probe signal, or pre-determined time intervals. Alternatively, these functions can be manually controlled by the operator. Figure 2.1 is a sketch of the pilot-scale kinetic mixer and Figure 2.2 is a photograph of the mixer installed at BNL.

Recycled plastics were initially incorporated into development testing of the kinetic mixer under select conditions to potentially enhance processing. Once the processing capabilities of the kinetic mixer had been defined using virgin low-density polyethylene, clearly defined feasibility tests were performed to determine recycled plastic processibility and waste form performance. Typically, five to ten replicate batches were processed under each test condition. Samples were fabricated from the kinetic mixer product including grab samples, compressive strength samples and leach testing samples. Grab samples were removed from each product sample to measure product density, homogeneity and consistency for multiple batches processed with the same test conditions. Waste form performance was evaluated by measuring compressive strength and the leaching of contaminants from the waste form. 


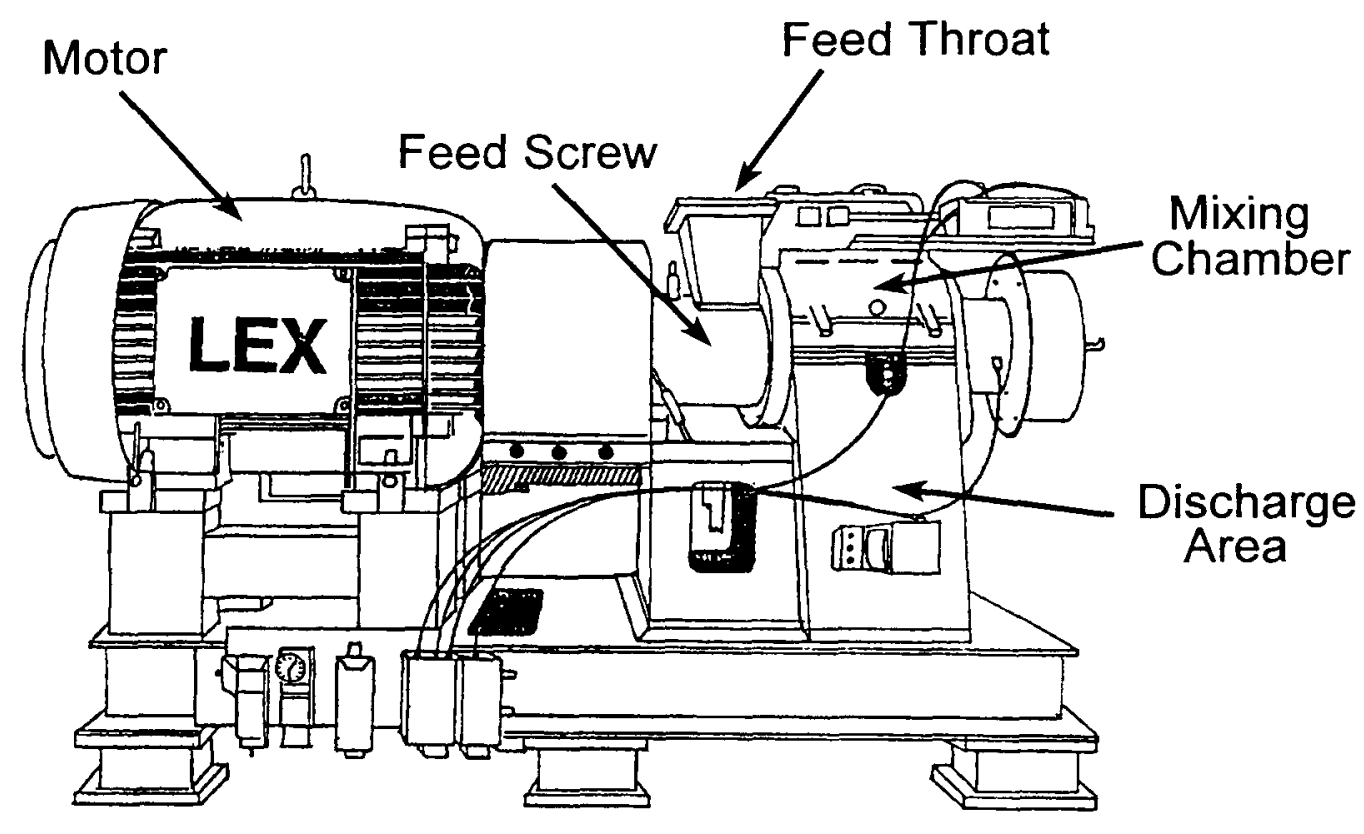

Figure 2.1. Sketch of kinetic mixer used during processibility testing.

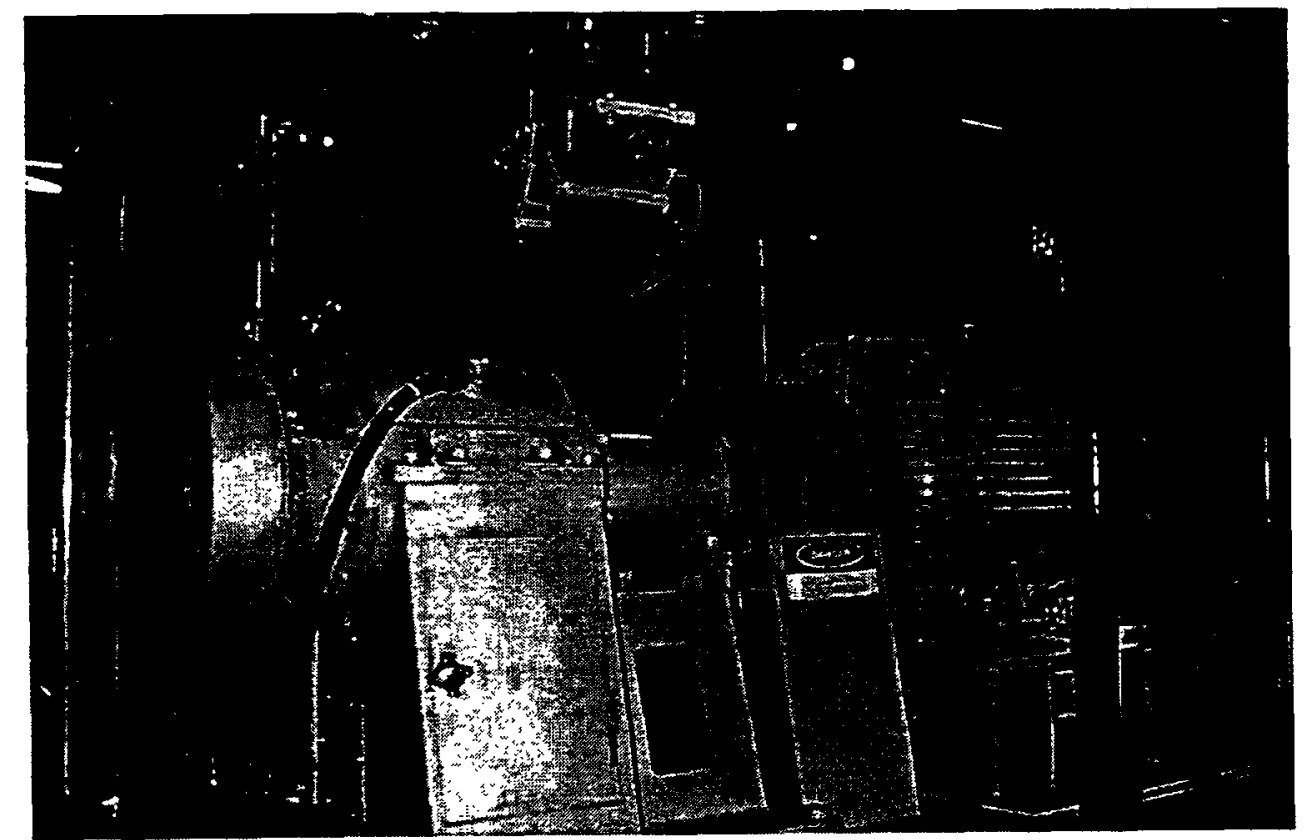

Figure 2.2. Kinetic mixer installed at BNL's Environmental \& Waste Technology Center. 


\subsection{Polymer Characterization}

During development of polymer encapsulation at BNL, the polymer type was investigated that would provide an optimum compromise between processibility, melt flow characteristics, durability, and maximum waste loading potential. [1,2] The potential waste loading drives the process economics since higher waste loadings result in fewer waste packages for storage, shipment and disposal and require less polymer for waste solidification. Polyethylene was selected since it is a simple polyolefin with relatively low cost in comparison to other polymer feedstocks, met all necessary performance requirements, was available in many different types, e.g., high, low and linear low-density, and was amenable to simple processing. Within each type of polyethylene, a broad range of melt flow properties, dependent on the molecular characteristics such as degree of crystallinity, degree of chain branching, molecular weight and molecular weight distribution, were also available.

In polymer microencapsulation, waste particles are physically encased in a polymer matrix in which individual waste particles are surrounded or coated by a layer of polymer. To achieve optimum waste encapsulation, a high melt flow and low melt viscosity is desired so that the molten polymer can mix with the waste and effectively coat the individual waste particles. Process development testing determined that injection molding grade low-density polyethylene resins worked well in this application. These resins typically have a melt index (MI) of $20(\mathrm{~g} / 10 \mathrm{~min})$ or higher. A high melt index corresponds to a high melt flow. The melt index is given in the units of grams per 10 minutes and refers to the quantity of molten polymer that will pass through a small capillary under a specified load during a measured time interval. Since the melt index is a rheological measurement of the polymer viscosity at one shear stress, it does not provide a prediction of the exact properties under processing conditions where shear stress is continually changing. However, a high melt index for polyethylene will generally work well for encapsulation processing.

As part of this effort, an investigate study was performed evaluating the polymer requirements for waste encapsulation and to identify potential sources of recycled plastics for use as waste encapsulating agents. A copy of this report, prepared by Dr. N. Merriam as a consultant to BNL, is included as Attachment A. Using the identified sources, a number of different postindustrial recycled plastics were procured. These plastics included LDPE, LLDPE, HDPE and PP, and are summarized in Table 2.1. The melt indices for some of these plastics was provided by the supplier and are included in the table. To characterize all the recycled plastics and predict the potential processing characteristics of the recycled plastics, the melt index was measured experimentally using a CSI MFI2 Melt Indexer (Melt Plastometer) in accordance with ASTM D1238. [3] In this standard, the equipment requirements for the capillary length and output die diameter are specified along with the applied load and operating temperatures for different plastics. Polyethylene, for example, has 7 different test conditions, of which, the most common is an applied load of $2.16 \mathrm{~kg}$ and an operating temperature of $190^{\circ} \mathrm{C}$. The experimentally measured melt indices of the recycled plastics obtained for this work and the virgin plastics are summarized in Table 2.2. The melt indices were measured at the specified test condition of $190^{\circ} \mathrm{C}$ with a $2.16 \mathrm{~kg}$ load and at a higher temperature of $200^{\circ} \mathrm{C}$ with a $2.16 \mathrm{~kg}$ load even though this is not a specified test condition. 
At the higher temperature, the measured values more accurately reproduced the values provided by the suppliers. The difference in values may be due to a slight buildup of polymer in the capillary tube or die. The test conditions used by the suppliers were not provided. For the recycled LDPE from JAM Plastics, the measured melt index was not close to the value provided by the supplier. For all other cases, the variation between the supplied values and the measured values was not deemed significant since the melt index was used only as a rough estimate for anticipated melt flow characteristics while processing.

Table 2.1. Quantity and source of recycled plastic procured for encapsulation testing.

\begin{tabular}{||l|l|l|l||}
\hline Plastic & Quantity & Description & Source \\
\hline \hline LDPE (JAM) & $400 \mathrm{lbs}$ & $\begin{array}{l}\text { Industrial recycle. Flake. Melt } \\
\text { index approx. 20. }\end{array}$ & $\begin{array}{l}\text { JAM } \\
\text { Buffalo, NY }\end{array}$ \\
\hline $\begin{array}{l}\text { HDPE (Clearzon } \\
\text { IM8) }\end{array}$ & $300 \mathrm{lbs}$ & $\begin{array}{l}\text { Pelletized blend of post-consumer } \\
\text { packaging materials. Melt index } \\
\text { approx. 6-8. }\end{array}$ & $\begin{array}{l}\text { Clearvue Polymers Inc. } \\
\text { Amsterdam, NY }\end{array}$ \\
\hline HDPE (Clearzon CP) & $300 \mathrm{lbs}$ & $\begin{array}{l}\text { Pelletized post-consumer } \\
\text { detergent and cleaner bottles. } \\
\text { Melt index approx. 0.55. }\end{array}$ & $\begin{array}{l}\text { Clearvue Polymers Inc. } \\
\text { Amsterdam, NY }\end{array}$ \\
\hline LLDPE & $300 \mathrm{lbs}$ & Pelletized post-industrial. & $\begin{array}{l}\text { Resources Plastics } \\
\text { Branford, Ontario }\end{array}$ \\
\hline HDPE & $300 \mathrm{lbs}$ & $\begin{array}{l}\text { Recycled from wire chopping } \\
\text { operation. }\end{array}$ & $\begin{array}{l}\text { Forrester Environmental } \\
\text { Services Inc. } \\
\text { Hampton, NH }\end{array}$ \\
\hline PP/HDPE & $1100 \mathrm{lbs}$ & $\begin{array}{l}\text { Post-consumer beverage bottle } \\
\text { reclaim after segregation of PET }\end{array}$ & $\begin{array}{l}\text { Pure Tech } \\
\text { Farmingdale, NY }\end{array}$ \\
\hline
\end{tabular}


Table 2.2. Recycled plastic melt indices ( $\mathrm{g} / 10 \mathrm{~min})$.

\begin{tabular}{|c|c|c|c|}
\hline Plastic & $\begin{array}{l}\text { Melt Index } \\
\text { Specification }\end{array}$ & $\begin{array}{l}\text { Measured Melt } \\
\text { Index } \\
\left(190^{\circ} \mathrm{C}, 2.16 \mathrm{~kg}\right) \\
\end{array}$ & $\begin{array}{l}\text { Measured Melt } \\
\text { Index } \\
\left(200^{\circ} \mathrm{C}, 2.16 \mathrm{~kg}\right)\end{array}$ \\
\hline Virgin LDPE (PE 1400) & 8 & $6.85^{\mathrm{a}}$ & 7.98 \\
\hline Virgin LDPE (PE 1008.5) & 22 & $18.6^{\mathrm{a}}$ & 21.8 \\
\hline Virgin LDPE (PE 1409) & 50 & $45.1^{\mathrm{a}}$ & 50 \\
\hline LDPE (JAM) & 20 & 3.07 & $3.53^{\mathrm{a}}$ \\
\hline HDPE (Clearzon IM8) & $6-8$ & 4.48 & $6.15^{\mathrm{a}}$ \\
\hline HDPE (Clearzon CP) & 0.55 & 0.42 & 0.46 \\
\hline LLDPE (Resource) & not given & 0.71 & 0.87 \\
\hline HDPE (Forrester) & not given & not measured & not measured \\
\hline PP/HDPE (Pure Tech) & not given & not measured & not measured \\
\hline
\end{tabular}

${ }^{\mathrm{a} B a s e d}$ on 3 replicates.

\subsection{Waste Surrogate Characterixation}

Polymer encapsulation with virgin plastics has been well demonstrated. The objective of this effort was to determine the impact of using recycled plastics as waste encapsulating agents. To accomplish this, two different waste surrogates were used as simulants of actual wastes. Surrogates were used instead of actual waste streams to minimize generation of secondary hazardous and radioactive wastes. The waste surrogates included a dried salt mixture, identified as RFP surrogate, and soil, identified as BNL soil. The salt mixture represents an evaporator concentrate, a solution containing $35 \%$ dissolved solids that is in storage and generated at different sites across the DOE complex. The salt surrogate used during this investigation was based on the chemical composition of salt wastes at the DOE Rocky Flats Plant (RFP). Table 2.3 summarizes the chemical composition of the salt surrogate. The surrogate was previously prepared at BNL as a solution, then dried and size reduced. The particle size distribution of the dried RFP surrogate varied between 250 and 2380 $\mu \mathrm{m}$. The soil surrogate represents contaminated soil also found throughout the DOE complex as well as at BNL. The soil was removed from the BNL site and sieved to less than approximately $10 \mathrm{~mm}$ to remove rocks and organic debris. 
Table 2.3. Chemical composition of RFP surrogate.

\begin{tabular}{|l|l|l||}
\hline Compound & Formula & Composition \% \\
\hline \hline Sodium Nitrate & $\mathrm{NaNO}_{3}$ & 37.3 \\
\hline Sodium Sulfate & $\mathrm{Na}_{2} \mathrm{SO}_{4}$ & 17.7 \\
\hline Sodium Fluoride & $\mathrm{NaF}$ & 5.2 \\
\hline Potassium Chloride & $\mathrm{KCl}$ & 31.6 \\
\hline Magnesium Chloride & $\mathrm{MgCl}_{2}$ & 2.0 \\
\hline Calcium Carbonate & $\mathrm{CaCO}_{3}$ & 6.2 \\
\hline
\end{tabular}

\section{RECYCLE POLYMER PROCESSING}

Kinetic mixing was investigated as a processing method for thermoplastic encapsulation of waste. This technique shows promise because of its robust design that permits processing of wastes with expanded particle size distributions and high moisture contents, e.g., up to $40 \%$. Virgin lowdensity polyethylene was used as the polymer binder during kinetic mixer development work in order to limit the total number of variable processing parameters. The waste surrogate loading was maintained at a constant 50 weight percent and the batch size was set at either 1 or $2 \mathrm{~kg}$. Once the mixer capabilities had been established, feasibility tests were conducted with recycled plastics to evaluate their impact on processing. The recycled plastics were substituted for or used in conjunction with virgin polymers.

In previous kinetic mixer process trials, the effect of varying melt index polymers was investigated. In comparing virgin low-density polyethylenes with melt indices of 8,22 and $50 \mathrm{~g} / 10$ min., polyethylene with a melt index of 22 provided the best results. These results differ from the optimal melt index for extrusion processing in which low-density polyethylene with a melt index of 50 performed best. Polyethylene with an $8 \mathrm{MI}$ (melt index of $8 \mathrm{~g} / 10 \mathrm{~min}$ ) has a relatively high melt viscosity and resulted in a significant amount of unencapsulated material discharged with each batch from the kinetic mixer. Polyethylene with a 50MI, which works exceptionally well with extrusion processing due to the constant temperature profile, required precise control over batch cycle time. This polymertended to overheat causing a significant decrease in melt viscosity and an unacceptable sticky product consistency. Processing of the $22 \mathrm{MI}$ polyethylene was easier to control and resulted in a homogeneous, well-mixed product.

Initial screening tests with recycled plastics were conducted with a pelletized mixture of recycled LDPE/LLDPE that was procured during FY96 from Mobil Chemical in Jacksonville, IL by R. Fitzpatrick, NYS Department of Economic Development. This plastic is not included in Table 2.1 since testing with this plastic was preliminary and was performed prior to establishing the kinetic mixer capabilities during FY97. In addition, only a small quantity was received. Testing included 
mixing this recycled polyethylene in a $2 \mathrm{~kg}$ batch with RFP salt surrogate at a waste loading of 50 $w t \%$. The results were not successful with most of the salt surrogate discharged from the mixer unencapsulated. These results provided the first indication as to the importance of the melt flow properties of the recycled plastics when used as encapsulants. The poor encapsulation results were due to the low melt flow of the recycled plastic mixture. The melt viscosity was likely too high under the experienced temperature and shear conditions to permit thorough mixing with the salt surrogate. Processing under these conditions with virgin low-density polyethylene produces successful results with a well mixed, homogeneous molten product. To compensate for the low melt flow of the recycled LDPE/LLDPE, a mixture with 50\% recycled LDPE/LLDPE and 50\% virgin LDPE (50 MI) was processed under the same conditions, i.e., $50 \mathrm{wt} \%$ RFP surrogate loading. The results were significantly improved resulting in a good product, although a small amount of salt particles were observed on the surface of the product. The amount of exposed salt was not quantified at this time but this occurrence had also been observed with virgin plastics and is attributable to the function and operation of the mixer.

Moisture removal experiments to determine the maximum moisture content that can be processed by the kinetic mixer were conducted with virgin LDPE and the RFP surrogate. Moisture contents up to $40 \%$ were processed although above $35 \%$ leakage of liquids from the mixing chamber discharge door occurred. This problem could be remedied by the use a flexible sealing surface or gasket. The cycle times necessary to evolve these high moisture contents were long and not practical from a processing standpoint. Cycle times for dry batches were typically 15-40 seconds and as long as 5-6 minutes for batches with $40 \%$ moisture. These cycle times were later determined to be highly dependent on the condition and length of the mixing blades. Longer blades cause significantly more shear and a correspondingly higher frictional heat generation rate. The mixing blades were modified near the end of this investigation resulting in much shorter cycle times for all batches. At this time, in order to reduce cycle times for batches containing high moisture contents, 10 and $20 \%$ quantities of recycled PP/HDPE (post-consumer beverage bottles) were added to the mixtures of virgin LDPE and RFP surrogate. This recycled plastic, from Pure Tech, is primarily composed of PP from bottle labels and caps with a lesser amount of HDPE from bottle base cups. The shredded PP caps were abrasive and were added to aid frictional heat generation. The addition of either 10 or $20 \%$ recycle to batches containing both 20 and $40 \%$ moisture improved the overall processibility of the wet wastes by decreasing cycle time and did not appear to reduce the effectiveness of the encapsulation. The product from batches containing $10 \%$ recycle PP/HDPE appeared homogeneous. The average density of grab samples measured $1.18 \mathrm{~g} / \mathrm{cm}^{3}$ with a percent error of 2.18 , indicating consistency over the five replicate runs. At 20\% recycle PP/HDPE, the cycles were more difficult to control probably due to the varied polymer composition which consisted of LDPE, PP and HDPE, each with different melting points. For 20\% recycle PP/HDPE, the grab sample density average was 1.12 $\mathrm{g} / \mathrm{cm}^{3}$ with a percent error of $7.23 \%$. This larger percent error shows the greater variation in product consistency over five replicate runs.

Feasibility tests to determine processibility of the different recycled plastics were conducted using both the BNL soil surrogate and RFP salt surrogate at a loading of 50 weight percent and $2 \mathrm{~kg}$ batch size, i.e., each batch contained $1 \mathrm{~kg}$ polymer and $1 \mathrm{~kg}$ surrogate. For all testing, the surrogates 
were dry with no added moisture. In most cases recycled plastics were blended together with virgin polyethylene in varying ratios depending on the projected melt flow and processing characteristics. Process testing results for each recycled plastic are summarized below.

\section{Recycle LDPE (JAM Plastics)}

This plastic consisted of white flakes with a reported melt index of 20 , as indicated by the supplier. The commercial or industrial source of this polymer was not known to the supplier. As mentioned in section 2.2 Polymer Type Characterization, trial measurement of the melt index for this plastic indicated values of 3-3.5 g/10 min., depending on the test condition. This discrepency may be due to the use of differing test parameters.

Processing with this recycled polymer was successful whether used as a direct substitute or in 60 or $80 \%$ proportion with virgin LDPE. Product appearance in replicate batches and cycle times were consistent and repeatable. The error in grab sample density measurements between replicate batches was also consistent except for a high of $6.08 \%$ for $80 \%$ R-LDPE with the BNL soil surrogate. Since processing at this and all others conditions was observed to be acceptable, the higher percent error is not deemed significant. The average cycle times were longer for the batches containing BNL soil as the waste surrogate because the total batch size during these tests was only $1 \mathrm{~kg}$. This was the only exception to using a $2 \mathrm{~kg}$ batch size during feasibility testing. Smaller batch sizes tend to have longer cycle times due to the smaller total mass and lower friction caused by particle to particle contact. Overall, this polymer works well alone as an encapsulant or combined with virgin polyethylene. Testing conditions for this recycle are summarized in Table 3.1.

\section{Table 3.1. Testing conditions and product density results for R-LDPE (JAM Plastics).}

\begin{tabular}{|l|l|c|l||}
\hline \multicolumn{1}{|c|}{ Composition } & Waste Surrogate & Average Cycle Time $^{\mathrm{b}}$ & \multicolumn{1}{|c|}{ Results $^{\mathrm{b}}$} \\
\hline \hline $100 \%$ R-LDPE & BNL soil & $1 \mathrm{~min} 29 \mathrm{sec}$ & $\begin{array}{l}\text { Sample density: } 1.16 \mathrm{~g} / \mathrm{cm}^{3} \\
\text { Error: } 2.01 \%\end{array}$ \\
\hline $\begin{array}{l}80 \% \text { R-LDPE } \\
20 \% \text { V-LDPE }\end{array}$ & BNL soil & $1 \mathrm{~min} 38 \mathrm{sec}$ & $\begin{array}{l}\text { Sample density: } 1.05 \mathrm{~g} / \mathrm{cm}^{3} \\
\text { Error: } 6.08 \%\end{array}$ \\
\hline $\begin{array}{l}60 \% \text { R-LDPE } \\
40 \% \text { V-LDPE }\end{array}$ & BNL soil & $1 \mathrm{~min} 38 \mathrm{sec}$ & $\begin{array}{l}\text { Sample density: } 1.10 \mathrm{~g} / \mathrm{cm}^{3} \\
\text { Error: } 3.81 \%\end{array}$ \\
\hline \hline $\begin{array}{l}100 \% \text { R-LDPE } \\
\text { RFP surrogate }\end{array}$ & 59 sec & $\begin{array}{l}\text { Sample density: } 1.04 \mathrm{~g} / \mathrm{cm}^{3} \\
\text { Error: } 3.67 \%\end{array}$ \\
\hline $\begin{array}{l}80 \% \text { R-LDPE } \\
20 \% \text { V-LDPE }\end{array}$ & RFP surrogate & $49 \mathrm{sec}$ & $\begin{array}{l}\text { Sample density: } 1.10 \mathrm{~g} / \mathrm{cm}^{3} \\
\text { Error: } 3.81 \%\end{array}$ \\
\hline $\begin{array}{l}60 \% \text { R-LDPE } \\
40 \% \text { V-LDPE }\end{array}$ & RFP surrogate & $44 \mathrm{sec}$ & $\begin{array}{l}\text { Sample density: } 1.07 \mathrm{~g} / \mathrm{cm}^{3} \\
\text { Error: } 4.65 \%\end{array}$ \\
\hline
\end{tabular}

${ }^{\mathrm{a}} 50$ weight percent loading. ${ }^{\mathrm{b}}$ Based on 5 replicates. ${ }^{\mathrm{c}} 22 \mathrm{MI}$ virgin LDPE. ${ }^{\mathrm{d}} 50 \mathrm{MI}$ virgin resin. 


\section{Recycle HDPE (Clearzon IM8, Clearvue Polymers)}

Clearzon IM8 recycled HDPE polymer is a black, reprocessed and pelletized blend of packaging materials. The melt index given by the supplier is $6-8 \mathrm{~g} / 10$ min which was verified experimentally. Process testing with Clearzon IM8 HDPE was conducted using both the BNL soil and RFP salt waste surrogates. Ratios of Clearzon IM8 HDPE/ virgin LDPE were 60, 80 and 100\% for the soil and 20,40 and $60 \%$ for the RFP surrogate. For all soil runs, the virgin polyethylene used had a melt index of 22. Feasibility testing with RFP surrogate, which was performed following the soil runs, was conducted using virgin polyethylene with a melt index of 50. The virgin polyethylene was changed to a higher melt flow in an attempt to compensate for the low melt flow of most of the recycled plastics tested.

The testing conditions and product density results for Clearzon IM8 HDPE are shown in Table 3.2. For each waste surrogate, the grab sample densities were repeatable and consistent. The low percent error indicated excellent batch-to-batch consistency and product homogeneity. In all cases, the processibility was acceptable except for the 100\% recycled HDPE batch with soil. In this case, the batch-to-batch consistency was poor and noticeable amounts of waste surrogate were dispersed while processing or were observed on the product surface upon cycle completion and product discharge. This phenomenon was observed but to a lesser extent with other compositions. In summary, based on processing results Clearzon IM8 HDPE can be used for waste encapsulation when added as part of a mixture ( $\leq 60-80 \mathrm{wt} \%)$ with virgin LDPE.

Table 3.2. Testing conditions and product density results for Clearzon IM8 Recycled HDPE

\begin{tabular}{|l|l|c|l||}
\hline Composition & Waste Surrogate $^{\mathrm{a}}$ & Average Cycle Time $^{\mathrm{b}}$ & \multicolumn{1}{|c||}{ Results $^{\mathrm{b}}$} \\
\hline \hline $100 \%$ R-HDPE & BNL soil & $46 \mathrm{sec}$ & $\begin{array}{l}\text { Sample density: } 1.22 \mathrm{~g} / \mathrm{cm}^{3} \\
\text { Error: } 8.95 \%\end{array}$ \\
\hline $\begin{array}{l}80 \% \text { R-HDPE } \\
20 \% \text { V-LDPE }\end{array}$ & BNL soil & $40 \mathrm{sec}$ & $\begin{array}{l}\text { Sample density: } 1.22 \mathrm{~g} / \mathrm{cm}^{3} \\
\text { Error: } 0.15 \%\end{array}$ \\
\hline $\begin{array}{l}60 \% \text { R-HDPE } \\
40 \% \text { V-LDPE }\end{array}$ & BNL soil & $41 \mathrm{sec}$ & $\begin{array}{l}\text { Sample density: } 1.20 \mathrm{~g} / \mathrm{cm}^{3} \\
\text { Error: } 1.50 \%\end{array}$ \\
\hline \hline $\begin{array}{l}60 \% \text { R-HDPE } \\
40 \% \text { V-LDPE }\end{array}$ & RFP surrogate & $50 \mathrm{sec}$ & $\begin{array}{l}\text { Sample density: } 1.16 \mathrm{~g} / \mathrm{cm}^{3} \\
\text { Error: } 1.27 \%\end{array}$ \\
\hline $\begin{array}{l}40 \% \text { R-HDPE } \\
60 \% \text { V-LDPE }\end{array}$ & RFP surrogate & $58 \mathrm{sec}$ & $\begin{array}{l}\text { Sample density: } 1.15 \mathrm{~g} / \mathrm{cm}^{3} \\
\text { Error: } 1.51 \%\end{array}$ \\
\hline $\begin{array}{l}20 \% \text { R-LDPE } \\
80 \% \text { V-LDPE }\end{array}$ & RFP surrogate & $33 \mathrm{sec}$ & $\begin{array}{l}\text { Sample density: } 1.18 \mathrm{~g} / \mathrm{cm}^{3} \\
\text { Error: } 1.08 \%\end{array}$ \\
\hline
\end{tabular}

${ }^{\mathrm{a}} 50$ weight percent loading. ${ }^{\mathrm{b}}$ Based on 5 replicates. ${ }^{\mathrm{c}} 22 \mathrm{MI}$ virgin LDPE. ${ }^{\mathrm{d}} 50 \mathrm{MI}$ virgin LDPE. 
Forrester Environmental Services recycled HDPE was a finely shredded, multi-colored mixture of high-density polyethylene generated during wire chopping operations. The melt index was neither measured nor provided by the supplier. Feasibility testing was limited to two compositions consisting of 20 and $40 \%$ recycle with 50MI virgin LDPE and the RFP surrogate. Waste surrogate processing in the kinetic mixing with this recycle was successful. The testing conditions and product density results for Forrester recycled HDPE are shown in Table 3.3. The grab sample densities were repeatable and consistent and the low percent error indicated excellent batchto-batch consistency for the $20 \%$ composition and good batch-to-batch consistency for the $40 \%$ composition. The average cycle time was considerably less for the batches containing $40 \%$ recycle. Just prior to this feasibility test, the mixing blades in the kinetic mixer were modified to increase blade length The blades were built up by electric arc welding and hard-faced with Stellite. This permitted a narrower clearance between the blade tip and the chamber wall resulting in much greater shear. Cycle times noticeably decreased but product homogeneity appeared to remain the same. Overall, from a processing standpoint, Forrester recycled HDPE worked well and had excellent processibility when added in ratios with virgin LDPE up to $40 \%$. 
Table 3.3. Testing conditions and product density results for Forrester recycled HDPE.

\begin{tabular}{||l|l|c|l||}
\hline \multicolumn{1}{|c|}{ Composition } & Waste Surrogate $^{\mathrm{a}}$ & Average Cycle Time $^{\mathrm{b}}$ & \multicolumn{1}{c||}{ Results $^{\mathrm{b}}$} \\
\hline \hline $\begin{array}{l}20 \% \mathrm{R}-\mathrm{HDPE} \\
80 \% \text { V-LDPE }\end{array}$ & RFP surrogate & $36 \mathrm{sec}$ & $\begin{array}{l}\text { Sample density: } 1.14 \mathrm{~g} / \mathrm{cm}^{3} \\
\text { Error: } 1.44 \%\end{array}$ \\
\hline $\begin{array}{l}40 \% \text { R-HDPE } \\
60 \% \text { V-LDPE }\end{array}$ & RFP surrogate & $12 \mathrm{sec}$ & $\begin{array}{l}\text { Sample density: } 1.21 \mathrm{~g} / \mathrm{cm}^{3} \\
\text { Error: } 2.47 \%\end{array}$ \\
\hline
\end{tabular}

a 50 weight percent loading. ${ }^{b}$ Based on 5 replicates. ${ }^{c} 50 \mathrm{MI}$ virgin LDPE.

\section{Recycled HDPE (Clearzon CP Clearvue Polymers)}

Clearzon CP recycled HDPE is a multi-colored, pelletized blend of post-consumer detergent and cleaner bottles. The melt index given by the supplier was 0.55 . This was considered too low for application to waste encapsulation but $20 \%$ of this plastic was blended with $80 \%$ virgin LDPE (50MI) to determine potential processing feasibility when used in small amounts. The processing conditions included a $50 \mathrm{wt} \%$ loading of RFP surrogate and $2 \mathrm{~kg}$ batch size. Testing results for this recycled polymer are shown in Table 3.4. The cycle time averaged 54 seconds over 5 batch replicates. However, it was difficult to discern precise flux times, presumably because the recycled HDPE had a higher melting point than the virgin LDPE so when sufficient frictional energy was generated to melt and reduce the melt viscosity of the recycled HDPE, the virgin LDPE was overheating and becoming sticky. Despite the processing difficulty, the product density averaged $1.14 \mathrm{~g} / \mathrm{cm}^{3}$ with a 0.97 percent error demonstrating excellent product homogeneity and batch-tobatch consistency. In summary, Clearzon $\mathrm{CP}$ recycled HDPE produced acceptable waste from products although some processing difficulty was encountered.

Table 3.4. Testing conditions and product density results for Clearzon $\mathrm{CP}$ recycled HDPE.

\begin{tabular}{|l|l|c|l||}
\hline \hline Composition & Waste Surrogate $^{\mathrm{a}}$ & Average Cycle Time $^{\mathrm{b}}$ & \multicolumn{1}{c|}{ Results $^{\mathrm{b}}$} \\
\hline $20 \% \mathrm{R}-\mathrm{HDPE}$ & RFP surrogate & $54 \mathrm{sec}$ & $\begin{array}{l}\text { Sample density: } 1.14 \mathrm{~g} / \mathrm{cm}^{3} \\
\text { Error: } 0.97 \%\end{array}$ \\
\hline
\end{tabular}

${ }^{a} 50$ weight percent loading. ${ }^{\mathrm{b}}$ Based on 5 replicates. ${ }^{\mathrm{c}} 50 \mathrm{MI}$ virgin LDPE.

\section{$\underline{\text { Recycled LLDPE (Resource Plastics) }}$}

Resource Plastics recycled LLDPE is a post-industrial, red and green, pelletized mixture of linear low-density polyethylene. The melt index for this recycle was not provided by the supplier. Feasibility testing with this recycle was conducted under one set of process conditions which included a $20 \%$ proportion blended with virgin LDPE (50MI), $50 \mathrm{wt} \%$ loading of RFP surrogate and $2 \mathrm{~kg}$ batch size. Testing results for Resource Plastics recycled LLDPE are shown in Table 3.5. Processing was successful with consistent cycle times which averaged 40 seconds over 5 replicates. Product density was $1.15 \mathrm{~g} / \mathrm{cm}^{3}$ with a 0.84 percent error indicating excellent product homogeneity 
and batch-to-batch consistency. Although not performed within the scope of this effort, higher proportions of this recycled plastic should be readily processible.

Table 3.5. Testing conditions and product density results for Resource recycled LLDPE.

\begin{tabular}{||l|l|c|l||}
\hline Composition & Waste Surrogate $^{\mathrm{a}}$ & Average Cycle Time $^{\mathrm{b}}$ & \multicolumn{1}{c|}{ Results $^{\mathrm{b}}$} \\
\hline \hline $20 \%$ R-HDPE & RFP surrogate & $40 \mathrm{sec}$ & $\begin{array}{l}\text { Sample density: } 1.15 \mathrm{~g} / \mathrm{cm}^{3} \\
\text { Error: } 0.84 \%\end{array}$ \\
\hline
\end{tabular}

${ }^{\mathrm{a}} 50$ weight percent loading. ${ }^{\mathrm{b}}$ Based on 5 replicates. ${ }^{\mathrm{c}} 50 \mathrm{MI}$ virgin LDPE.

\section{$\underline{\text { Recycled PP/HDPE (Pure Tech) }}$}

Pure Tech recycled PP/HDPE consisted of a multicolored mixture of PP and HDPE with a small fraction $(<1 \%)$ of poly(ethylene terephthalate) (PET) from post-consumer beverage bottle reclaim. Expectations for this recycled plastic were low for use as an encapsulating polymer because of its diverse composition consisting of different types of PP from both labels and caps, HDPE from base cups and the small fraction of PET. Each of these polymers in addition to the virgin LDPE have a slightly different melting temperature thereby increasing the processing complexity. This recycle was tested previously with successful results during moisture removal capacity testing of the mixer in an effort to reduce lengthy cycle times by aiding in frictional heat generation. In this feasibility test conducted at one set of processing conditions, a $20 \%$ proportion of recycle was added to $50 \mathrm{MI}$ virgin LDPE in a $2 \mathrm{~kg}$ batch containing $50 \mathrm{wt} \% \mathrm{RFP}$ surrogate. Table 3.6 summarizes testing conditions and processing results. Processing was successful with cycle times that averaged 13 seconds based on 5 replicates. The short cycle times were a direct result of the mixing blade modification, completed just prior to this feasibility test. Cycles were easily controlled because of the short time necessary to melt and mix the materials in the mixer. The product density average was $1.19 \mathrm{~g} / \mathrm{cm}^{3}$ with a $4.57 \%$ error. Visual observations of the product homogeneity indicated some variation between replicate batches. In summary, Pure Tech recycled PP/HDPE was an acceptable feedstock when combined with $80 \%$ virgin LDPE. Slightly higher quantities of this recycle may also be acceptable.

Table 3.6. Testing conditions and product density results for Pure Tech recycled PP/HDPE.

\begin{tabular}{|l|l|c|c|}
\hline \multicolumn{1}{|c|}{ Composition } & Waste Surrogate $^{\mathrm{a}}$ & Average Cycle Time $^{\mathrm{b}}$ & \multicolumn{1}{c|}{ Results $^{\mathrm{b}}$} \\
\hline $\begin{array}{l}20 \% \text { R-PP/HDPE } \\
80 \% \text { V-LDPE }\end{array}$ & RFP surrogate & $13 \mathrm{sec}$ & $\begin{array}{l}\text { Sample density: } 1.19 \mathrm{~g} / \mathrm{cm}^{3} \\
\text { Error: } 4.57 \%\end{array}$ \\
\hline
\end{tabular}

a 50 weight percent loading. ${ }^{\mathrm{b}}$ Based on 5 replicates. ${ }^{\mathrm{c}} 50 \mathrm{MI}$ virgin LDPE. 


\section{PRODUCT CHARACTERIZATION AND PERFORMANCE}

Evaluating the overall effectiveness of recycled polymers for waste encapsulation involves ascertaining the processibility (discussed in Section 3 ) and the product performance. To establish the product or waste form performance, mechanical integrity testing and leach testing were performed. These factors are important in determining whether a waste form meets minimum criteria for safe disposal and provide long-term containment of the hazardous or radioactive components. Additional waste form testing can be conducted such as immersion testing to simulate aqueous environments, biological stability, radiation stability and thermal cycling but were beyond the scope of this study. Previous studies $[1,2,4,5,6,7,8]$ have shown polyethylene to excel as a waste encapsulant so the scope of testing was limited to mechanical integrity and leachability in order to establish a product performance foundation.

\subsection{Waste Form Mechanical Integrity}

Compressive strength testing was performed in order to quantify the mechanical integrity of the recycled plastic waste forms. Right cylindrical specimens with nominal $5.1 \mathrm{~cm}(2 \mathrm{in})$ by 10.2 $\mathrm{cm}$ (4 in) dimensions were fabricated during processibility testing using brass molds. While the specimens were cooling, a slight load was applied to ensure flat surfaces on the top and bottom. Testing was conducted in accordance with ASTM D695, "Standard Test Method for Compressive properties of Rigid Plastics" using an Instron 5582 Materials Tester.[9] Each sample was compressed uniaxially at a constant loading rate of $1.0 \pm 0.5 \mathrm{~mm} / \mathrm{min}$ until sample failure by either plastic deformation or ductile fracture. The results obtained included a plot of stress versus strain, percent deformation and maximum compressive strength. For specimens at a given polymer and waste composition, three replicate samples were tested to verify statistical significance. Although there is no minimum waste form compressive strength required for disposal of DOE hazardous and radioactive wastes, the Nuclear Regulatory Commission (NRC) recommends a minimum 4.14 MPa (60 psi) for licensable polymer solidification processes.

Compressive strength testing was conducted on recycled plastic waste forms containing 50 weight percent RFP surrogate. Testing results include a plot of stress versus strain, maximum compressive strength, percent deformation and failure mechanism. The percent deformation is calculated as the percent difference between initial sample height less final sample height divided by initial sample height. At lower waste loadings, the failure mechanism is typically due to plastic deformation due to the total volume of plastic in the final waste form. However, as the loading is increased, the ductile limit of the composite may be exceeded resulting in a sample failure by fracture. The measured compressive strength and percent deformation, based on 3 replicates, at failure of nominal $5.1 \mathrm{~cm}(2$ in) by $10.2 \mathrm{~cm}$ (4 in) right cylindrical specimens which were formulated during processibility testing are summarized in Table 4.1. All samples were above the recommended NRC minimum guideline of $4.14 \mathrm{MPa}(60 \mathrm{psi})$ for compressive strength. The failure meachanism for all samples was ductile fracture with the percent deformation at failure varying from a high of 45-50 for samples comprised of LDPE and approximately 15-25 for samples containing HDPE. 
Table 4.1. Compressive strength of recycled plastic waste forms.

\begin{tabular}{|c|c|c|c|c|}
\hline \multirow[t]{2}{*}{ Sample } & \multicolumn{3}{|c|}{ Max. Compressive Strength } & \multirow{2}{*}{$\begin{array}{c}\% \text { Deformation } \\
\text { at Failure }\end{array}$} \\
\hline & $(\mathrm{MPa})$ & (psi) & $\%$ error & \\
\hline $\begin{array}{l}\text { Baseline }^{\mathrm{a}} \\
\text { 100\% V-LDPE }(50 \mathrm{MI})\end{array}$ & $16.4 \pm 0.79$ & $2380 \pm 115$ & 4.8 & not measured \\
\hline $100 \%$ R-LDPE (JAM) & $12.36 \pm 1.54$ & $1793 \pm 223$ & 12.4 & 50 \\
\hline $\begin{array}{l}80 \% \text { R-LDPE (JAM) } \\
20 \% \text { V-LDPE }\end{array}$ & $10.29 \pm 5.45$ & $1492 \pm 790$ & 52.9 & 49.9 \\
\hline $\begin{array}{l}60 \% \text { R-LDPE (JAM) } \\
40 \% \text { V-LDPE }\end{array}$ & $8.58 \pm 1.35$ & $1245 \pm 196$ & 15.8 & 45.2 \\
\hline $\begin{array}{l}60 \% \text { R-HDPE (Clearzon IM8) } \\
40 \% \text { V-LDPE }\end{array}$ & $15.18 \pm 0.81$ & $2202 \pm 117$ & 5.3 & 13 \\
\hline $\begin{array}{l}40 \% \text { R-HDPE (Clearzon IM } 8 \text { ) } \\
60 \% \text { V-LDPE }\end{array}$ & $13.66 \pm 2.13$ & $1982 \pm 309$ & 15.6 & 15.1 \\
\hline $\begin{array}{l}20 \% \text { R-HDPE (Clearzon IM8) } \\
80 \% \text { V-LDPE }\end{array}$ & $10.44 \pm 0.41$ & $1515 \pm 60$ & 3.9 & 15.22 \\
\hline $\begin{array}{l}20 \% \text { R-HDPE (Clearzon CP) } \\
80 \% \text { V-LDPE }\end{array}$ & $11.43 \pm 1.43$ & $1658 \pm 207$ & 12.5 & 15.09 \\
\hline $\begin{array}{l}20 \% \text { R-LLDPE (Resource Plastics) } \\
80 \% \text { V-LDPE }\end{array}$ & $11.67 \pm 1.43$ & $1691 \pm 208$ & 12.3 & 30 \\
\hline $\begin{array}{l}40 \% \text { R-HDPE (Forrester) } \\
60 \% \text { V-LDPE }\end{array}$ & $12.91 \pm 1.42$ & $1873 \pm 206$ & 11.0 & 22.1 \\
\hline $\begin{array}{l}20 \% \text { R-HDPE (Forrester) } \\
80 \% \text { V-LDPE }\end{array}$ & $11.85 \pm 0.28$ & $1718 \pm 33$ & 1.92 & 24.9 \\
\hline $\begin{array}{l}20 \% \text { R-PP/HDPE (Pure Tech) } \\
80 \% \text { V-LDPE }\end{array}$ & $12.46 \pm 3.06$ & $1807 \pm 444$ & 24.6 & 11.7 \\
\hline
\end{tabular}

${ }^{a}$ See reference 5 .

\subsection{Waste Form Leachability}

Leach testing was conducted on recycled plastic waste forms to measure and compare product performance. Waste form test samples were fabricated during feasibility testing as $2.5 \mathrm{~cm}$ ( 1 in) diameter by $2.5 \mathrm{~cm}$ ( 1 in) high right cylinders. Testing was performed in accordance with the Accelerated Leach Test, ASTM C1308, a method developed at BNL for waste form leachability projections.[10] The test protocol specifies 13 leachate changes over an eleven day period. If the leach data fits a diffusion controlled model, a prediction may be made of leach rates over longer times for larger waste forms. Five waste form samples at different polymer combinations with RFP 
surrogate and one baseline were tested at ambient temperature. Each series tested included three replicates. One additional test was performed at an elevated temperature of $50^{\circ} \mathrm{C}$. The concentration of sodium, chemically similar to cesium, a common radionuclide contaminant, was measured in each leachate solution using a Varian Inductively Coupled Plasma (ICP) Spectrometer. The results obtained included the incremental and cumulative fraction leached (IFL and CFL) of Na, the diffusion coefficient, and the goodness-of-fit to the diffusion model. Based on the diffusion model, the cumulative fraction leached from full-scale waste forms over 300 years was calculated.

. Over an 11 day period, the fraction of sodium $(\mathrm{Na})$ leached from the samples was measured and calculated as the incremental or cumulative fraction leached. Sodium was used to measure leachability because it has similar leach behavior to cesium, an isotope commonly present in typical low-level radioactive waste, due to the same chemical periodicity. The initial quantity of sodium was known based on the composition of the RFP surrogate which was encapsulated in each waste form sample at a 50 weight percent loading. Table 4.2 summarizes the data (average of 3 replicates) for cumulative fraction leached of sodium for the three recycled polymer compositions and a run at an elevated temperature of $50^{\circ} \mathrm{C}$ compared with a baseline run of virgin LDPE. All data indicated a diffusion controlled leach mechansim, as is usually the case for polymer waste forms, so a diffusion model was generated. Table 4.2 contains the diffusion coefficients and the error in the diffusion model. An error value of less than $1 \%$ corresponds to an excellent model fit.

A plot of the data, CFL versus time, which represents an average of three replicate runs, is shown in Figure 4.1. It can be seen that each curve follows the same trend regardless of the composition. An additional replicate was conducted of the $60 \%$ R-LDPE (JAM), $40 \%$ virgin LDPE at an elevated temperature of $50^{\circ} \mathrm{C}$ in order accelerate the leach rate. Higher temperatures should accelerate leaching because contaminant solubility is temperature dependent and will increase accordingly. The leach rate was slightly but not significantly higher at the elevated temperature. Included in Figure 4.1 are the plus and minus two sigma error bars for the baseline runs with 100\% virgin LDPE. This represents the statistical 95 percent confidence interval for the baseline run. All data, regardless of the composition, is found to fall within this range. The cumulative fraction leached did not exceed 0.08 or $8 \%$ of the initial source term of sodium in the samples over the entire leach test. The lowest leaching was observed with $100 \%$ recycled LDPE (JAM), actually performing better than the virgin LDPE. The mixture of $60 \%$ R-LDPE (JAM)/40\% virgin-LDPE had nearly identical leaching to the baseline of $100 \%$ virgin-LDPE. The greatest leaching was from the elevated temperature run and the batches comprised of 20\% R-HDPE (Clearzon IM8)/80\% virgin-LDPE. In general, leach rates were low and all samples fabricated from recycled plastics performed as well or better in leaching tests than those fabricated from virgin polymers. .

Using the diffusion coefficients calculated by the ALT computer software, the leach rates were extrapolated to calculate the CFL for full-scale waste forms over a period of 300 years. This time frame was selected because it represents a period of 10 half-lives for the most long-lived isotope (Cs-137) commonly found in low-level radioactive waste, after which time the activity has decayed to negligible levels. A full-scale waste form was assumed to be equivilent to the volume of a 55-gallon drum. The resulting CFL at 300 years was calculated to be highest for the run at 
elevated temperature, as expected, at 0.282 or $28.2 \%$. The other calculated CFLs were $0.205,0.138$, 0.160 and 0.206 for the baseline (100\% virgin-LDPE), 100\% R-LDPE (JAM), 60\% R-LDPE (JAM) $/ 40 \%$ virgin-LDPE, and $20 \%$ R-HDPE (Clearzon IM8)/80\% virgin-LDPE. respectively. The calculated CFLs at the completion of the Accelerated Leach Test and extrapolated to 300 years for full-scale waste forms are summarized in Table 4.3 
Table 4.2. Accelerated Leach Test results; CFL versus time for recycled plastic waste forms.

\begin{tabular}{|c|c|c|c|c|c|}
\hline $\begin{array}{c}\text { Time } \\
\text { (days) }\end{array}$ & $100 \%$ V-LDPE & $100 \%$ R-LDPE & $\begin{array}{l}60 \% \text { R-LDPE } \\
40 \% \text { V-LDPE } \\
\end{array}$ & $\begin{array}{l}20 \% \text { R-HDPE } \\
80 \% \text { V-LDPE } \\
\end{array}$ & $\begin{array}{c}60 \% \text { R-LDPE }^{\mathrm{b}, 11} \\
40 \% \text { V-LDPE } \\
\end{array}$ \\
\hline 0.08 & $1.79 \mathrm{e}-02$ & $1.78 \mathrm{e}-02$ & $2.59 \mathrm{e}-02$ & $2.72 \mathrm{e}-02$ & $1.36 \mathrm{e}-02$ \\
\hline 0.33 & $2.72 \mathrm{e}-02$ & $2.40 \mathrm{e}-02$ & $3.48 \mathrm{e}-02$ & $3.69 \mathrm{e}-02$ & $2.01 \mathrm{e}-02$ \\
\hline 1.06 & $3.60 \mathrm{e}-02$ & $3.15 \mathrm{e}-02$ & $4.22 \mathrm{e}-02$ & $4.72 \mathrm{e}-02$ & $3.02 \mathrm{e}-02$ \\
\hline 2.06 & $4.16 \mathrm{e}-02$ & $3.50 \mathrm{e}-02$ & $4.63 \mathrm{e}-02$ & $5.28 \mathrm{e}-02$ & $3.71 \mathrm{e}-02$ \\
\hline 3.06 & $4.55 \mathrm{e}-02$ & $3.75 \mathrm{e}-02$ & $4.96 \mathrm{e}-02$ & $5.69 \mathrm{e}-02$ & $4.30 \mathrm{e}-02$ \\
\hline 4.06 & $4.90 \mathrm{e}-02$ & $3.97 e-02$ & $5.19 c-02$ & $5.98 \mathrm{e}-02$ & $4.85 \mathrm{e}-02$ \\
\hline 5.06 & $5.21 \mathrm{e}-02$ & $415 e-02$ & $5.43 e-02$ & $6.30 \mathrm{e}-02$ & $5.40 \mathrm{e}-02$ \\
\hline 6.06 & $5.53 \mathrm{e}-02$ & $4.37 \mathrm{e}-02$ & $5.66 \mathrm{e}-02$ & $6.56 \mathrm{e}-02$ & $5.90 \mathrm{e}-02$ \\
\hline 7.06 & $5.85 \mathrm{e}-02$ & $4.59 \mathrm{e}-02$ & $5.88 \mathrm{e}-02$ & $6.85 \mathrm{e}-02$ & $6.37 e-02$ \\
\hline 8.06 & $6.17 \mathrm{e}-02$ & $4.81 \mathrm{e}-02$ & $6.10 \mathrm{e}-02$ & $7.12 \mathrm{e}-02$ & $6.82 \mathrm{e}-02$ \\
\hline 9.06 & $6.44 \mathrm{e}-02$ & $4.97 \mathrm{e}-02$ & $6.28 \mathrm{e}-02$ & $7.35 \mathrm{e}-02$ & $7.22 \mathrm{e}-02$ \\
\hline 10.06 & $6.71 \mathrm{e}-02$ & $5.15 \mathrm{e}-02$ & $6.48 \mathrm{e}-02$ & $7.58 \mathrm{e}-02$ & $7.67 e-02$ \\
\hline 11.06 & $6.98 \mathrm{e}-02$ & $5.33 \mathrm{e}-02$ & $6.67 \mathrm{e}-02$ & $7.80 \mathrm{e}-02$ & $8.07 e-02$ \\
\hline \multicolumn{6}{|c|}{ Diffusion Model } \\
\hline $\mathrm{D}(\mathrm{cm} / \mathrm{sec})$ & $4.40 \mathrm{e}-10$ & $1.91 \mathrm{e}-10$ & $2.63 \mathrm{e}-10$ & $4.44 \mathrm{c}-10$ & $8.45 \mathrm{c}-10$ \\
\hline Error $(\%)$ & 0.63 & 0.80 & 0.87 & 0.96 & 0.26 \\
\hline
\end{tabular}

${ }^{\text {" }}$ virgin LDPE $(50 \mathrm{MI}) .{ }^{\mathrm{b}}$ recycle LDPE (JAM). ${ }^{\circ}$ recycle HDPE (Clearzon IM8). ${ }^{\mathrm{u}}$ test conducted at $50^{\circ} \mathrm{C}$, one replicate. 


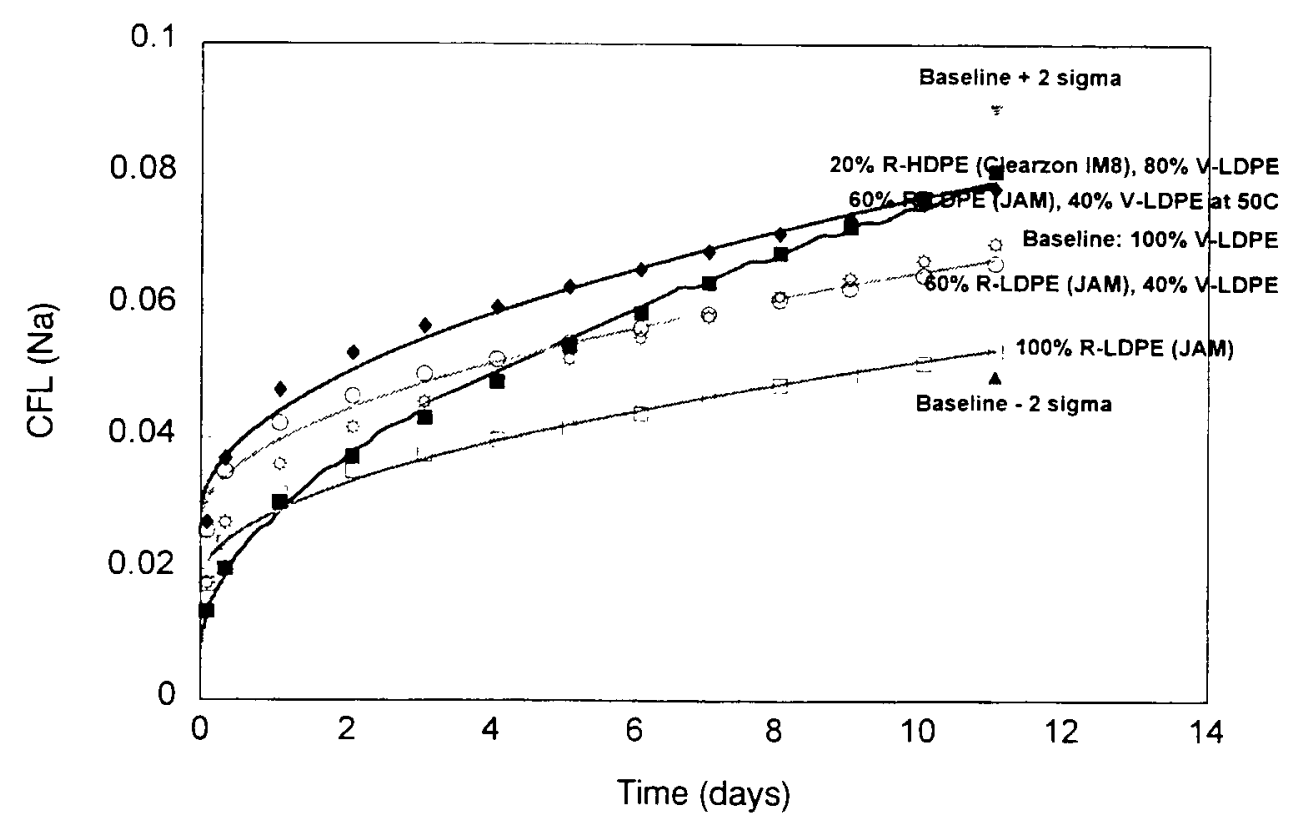

Figure 4.1. ALT leach results for waste forms containing 50 wt $\%$ RFP surrogate.

Table 4.3. Comparison of CFL for Na at ALT completion and 300 year extrapolation.

\begin{tabular}{|c|c|c|c|c|c|}
\hline CFL & $100 \% \mathrm{~V}-\mathrm{LDP} \mathrm{E}^{\mathrm{a}}$ & $100 \%$ R-LDPE ${ }^{b}$ & $\begin{array}{l}60 \% \text { R-LDPE } \\
40 \% \text { V-LDPE }\end{array}$ & $\begin{array}{l}20 \% \mathrm{R}_{-H D P E}^{\mathrm{c}} \\
80 \% \mathrm{~V}-\mathrm{LDPE}^{\mathrm{a}}\end{array}$ & $\begin{array}{l}60 \% \mathrm{R}-\mathrm{LDPE}^{\mathrm{b}, d} \\
40 \% \mathrm{~V}-\mathrm{LDPE}^{\mathrm{a}}\end{array}$ \\
\hline $\begin{array}{l}\text { @ ALT } \\
\text { completion }\end{array}$ & 0.0697 & 0.0532 & 0.0667 & 0.0780 & 0.0807 \\
\hline $\begin{array}{l}\text { (a) } 300 \text { year } \\
\text { extrapolation }\end{array}$ & 0.205 & 0.138 & 0.160 & 0.206 & 0.282 \\
\hline
\end{tabular}

\section{CONCLUSIONS}

Feasibility tests were conducted to investigate the use of recycled plastics as waste encapsulating agents. BNL has developed a thermoplastic encapsulation technology to solidify hazardous, radioactive and mixed wastes for disposal. This technology has been well demonstrated using extrusion as the processing method and virgin low-density polyethylene as the waste binder. In conjunction with this effort, co-funding was provided by the DOE Mixed Waste Focus Area (EM50) to investigate the use of kinetic mixing as an alternative processing method due to potential process improvements such as higher permissible waste moisture contents and a broader particle size distribution. Following initial testing to assess the capabilities of the kinetic mixer, recycled plastics were substituted for or used in conjunction with virgin polyethylene. Recycled plastics included LDPE, 3 types of HDPE, LLDPE and a mixture of PP and HDPE. The effectiveness of the recycled 
plastics in this application was judged based on both processing and waste form performance considerations.

The selection of the appropriate compositional percentage of recycled plastic to be used in substitution for virgin LDPE was based upon the melt index. The melt index for most of the plastics was provided by the supplier and was also measured experimentally. A relatively high melt index is required so that the melt viscosity of the polymer permits thorough mixing with the waste particles. In this process, virgin LDPE with a melt index of 22 was determined to provide the best compromise for processibility and encapsulation effectiveness. As expected, the recycled LDPE from JAM Plastics with a melt index of $20 \mathrm{~g} / 10 \mathrm{~min}$. had excellent processibility and waste form performance. This recycle was substituted completely for the virgin LDPE as well as used in 60 and $80 \%$ proportions. Each composition produced favorable results. Compressive strength and leachability results were equivalent to those achieved with virgin LDPE. This recycle is recommeded for use in waste encapsulation processing.

The recycle with the next highest melt index was HDPE from Clearvue Polymers, identified as Clearzon IM8. This recycle, with a 6-8 melt index, was tested as a 20,40,60, 80 and $100 \%$ substitute for virgin LDPE. Processing results were favorable up to a maximum of $60 \%$. Above this the melt viscosity was too high for proper mixing with the waste surrogates. Compressive strength testing at 20,40 and 60\% proportion and leach testing at 20\% produced acceptable performance results, comparable with those of virgin LDPE.

The other recycled plastics were blended with virgin LDPE at ratios $\leq 40 \%$ due to their low melt indices. At blends containing 20\% recycled polymer and $80 \%$ virgin LDPE, HDPE from Clearvue Polymers (Clearzon CP), LLDPE from Resource Plastics, HDPE from Forrester Environmental Services and PP/HDPE from Pure Tech each produced successful processing results. Recycled HDPE from Forrester also worked well at blends $\leq 40 \%$ Mechanical integrity of these formulations were all equivilent with virgin LDPE and well above the Nuclear Regulatory Commission recommended 4.14 $\mathrm{MPa}$ (60 psi). No leach testing was performed with these formulations but results are expected to be similar to other tested samples.

In summary, recycle plastics may be successfully used to substitute for virgin polymers as feedstock in polymer microencapsulation applications. The optimum composition for inclusion of recycled plastics is dependent on the melt index which, in turn, determines the melt flow characteristics. In this study, one recycle stream of LDPE with a 22 melt index performed well as a direct sustitute for virgin LDPE from both a processing and waste form performance standpoint. Numerous other recycled polymers worked well when blended with virgin LDPE. Since polymer encapsulation has wide application to the large volume of hazardous, radioactive and mixed wastes requiring treatment by solidification, even recycled plastics substituted in smaller proportions such as 20 or $40 \%$ have merit and a large potential market. 


\section{REFERENCES}

1. Kalb, P.D. and P. Colombo, "Polyethylene Solidification of Low-Level Wastes," BNL 51867, Brookhaven National Laboratory, Upton, NY, October 1984.

2. Kalb, P.D., J.H. Heiser, III, and P. Colombo, " Polyethylene Encapsulation of Nitrate Salt Wastes: Waste Form Stability, Process Scale-up, and Economics," BNL- 52293. Brookhaven National Laboratory, Upton NY. July 1991.

3. ASTM, "Standard Test Method for Flow Rates of Thermoplastics by Extrusion Plastometer," D1238, American Society for Testing and Materials, Philadelphia, PA.

4. Kalb, P.D., and M. Fuhrmann, "Polyethylene Encapsulation of Single-Shell Tank Wastes," BNL-52365, Brookhaven National Laboratory, Upton, NY, September 1992.

5. Kalb, P.D., and P.R. Lageraaen, "Polyethylene Encapsulation Full-Scale Technology Demonstration," BNL-52478, Brookhaven National Laboratory, Upton, NY, 1995.

6. Lageraaen, P.R., B.R. Patel, P.D. Kalb, and J.W. Adams, "Treatability Studies for Polyethylene Encapsulation of INEL Low-Level mixed Wastes," BNL-62620, Brookhaven National Laboratory, Upton. NY, October 1995.

7. Kalb, P.D., J.H. Heiser, and P. Colombo, "Long-Term Durability of Polyethylene for Encapsulation of Low-Level Radioactive, Hazardous, and Mixed Wastes," Emerging Technologies in Hazardous Waste Management III, D.W. Tedder and R.G. Pohland, eds., American Chemical Society Symposium Series 518, Washington, D.C., 1993.

8. Kalb, P.D., and P.R. Lageraaen, "Full-Scale Technology Demonstration of a Polyethylene Encapsulation Process for Radioactive, Hazardous, and Mixed Wastes," Journal of Environmental Science and Health, Vol. A31, No. 7, pp. 1767-1780, 1996.

9. ASTM, "Standard method of Test for Compressive Properties of Rigid Plastics, "D695, American Society for Testing and Materials, Philadelphia, PA.

10. ASTM, "Accelerated Leach Test for Diffusive Releases from Solidified Waste and a Computer Program to model Diffusive, Fractional Leaching from Cylindrical Waste Forms," C1308. American Society for Testing and Materials, Philadelphia, PA. 